\title{
Medical Breakthrough of Anthropometric Methods as Basis for 3D Digital Modelling of Indonesian Female Facial Type (Descriptive-analytic-applied Study)
}

\author{
Ulfah Elfiah $^{1}$, M R Hutagalung ${ }^{1}$, D S.Perdanakusuma ${ }^{1}$, Phill T Koesbandriati ${ }^{2}$, and Agus Windharto ${ }^{3}$
}

\begin{abstract}
Three dimension (3D) face model based on anthropometric data is used as facial plastic surgery simulation, which can be used for setting up a pre-surgery communication between a surgeon and his patient. All this time, Indonesian plastic surgeons have made preoperative and intraoperative evaluation based on the patient's aesthetic sense or desire, and the surgeon's operative technique preferences referring to subjective visual "landmark" and Caucasian parameters instead of referring to parameters of the normal Indonesian face which have not yet been established until now. The research objective is creating 3D digital modeling of the Indonesian facial type, which will provide useful reference points speedily, accurately and efficiently, in facial aesthetic and reconstructive plastic surgery and other interdisciplinary fields. The Methods is an applied study using anthropometric data as basis for formulation of 3D digital modeling of Indonesian facial type, performed 17-25 years old students without history of facial reconstruction and orthodontics. The first step was to distribute questioners to obtain criteria of normal and attractive female faces. Lateral cephalometric, photometric; direct anthropometric and photography were performed. Then the analysis results were applied to $3 D$ modeling programs to make the Indonesian facial type digital geometry overview. Furthermore, the image was interpreted by an expert before concluding the end result. The results are description of distinguishing parameters between normal and attractive groups by discriminant test included nasal bridge index, binocular width, nasal tip protrusion, mouth width index. According to cephalometry and photometry results, the Indonesian face was more convex than the Caucasian face. Anthropometric, photometric and lateral cephalometric measurements played a significant role in differentiating the Indonesian face between normal and attractive also from faces of other races. $3 D$ digital woman models can serve as instruments for characterizing normal and attractive faces visually.
\end{abstract}

Keywords - reciprocating compressor, valve seat, vibration, pressure.

\section{INTRODUCTION}

$\mathrm{F}$ ace is one of the most important part in humans because it can represent any expression of the human soul itself, even the harmony of each part of the face can affect the overall appearance of a person. 1 Therefore, the changing face due to trauma, congenital or aging processes will cause a disruption in terms of appearance and function. Plastic surgery would be solution for solving this problem. The phenomenon among Indonesian people shows that demand for plastic surgery of the face is higher both in reconstruction and aesthetic surgeries. In fact, the rate of surgical repair of the nose and eyelids are $21.9 \%$ of the total percentage of the most popular plastic surgical procedures [2].

Therefore, proper preoperative adjunct diagnostic procedure and surgical techniques are required to correct the deformity and dysfunction. One of the basic procedures that can be used to achieve optimal results in plastic surgery is obtaining data consisting of preoperative facial size, shape and occlusal type. 3 Facial animation model is another procedure for operative planning and predicting surgical outcome visually (figure

${ }^{1}$ Ulfah Elfiah, M R Hutagalung, and D S. Perdanakusuma are with Departement of Plastic Surgery, Universitas Airlangga, Surabaya, Indonesia. E-mail: elfiah@yahoo.com.

${ }^{2}$ Phill $\mathrm{T}$ Koesbandriati is with Departement of Anthropology, Universitas Airlangga, Surabaya, Indonesia.

${ }^{3}$ Agus Windharto is with Departement of Industrial Design, Faculty of Civil Engineering and Planning, Institut Teknologi Sepuluh Nopember, Surabaya, 60111, Indonesia. E-mail: itsdesigncenter@yahoo.com.
$1)$. These procedures are commonly used in developed countries [4-6].

Indonesian plastic surgeons still make preoperative planning based on patients' demands and their experience, referring to Caucasian parameters due to the limited data derived from our own people. Thisese parameters are often difficult if not impossible to use, because the measurements are the average of samples derived from a different race or geography. The application of Caucasian parameters will also affect the final operative result. The characteristic of Indonesian face will be lost.[3-4,6]

Therefore, these reasons motivated the plastic surgery department of Surabaya to conduct a basic research from 2011 until 2012 to establish a baseline parameter of the Indonesian face. Interdisciplinary experts were involved such as anthropologists, orthodontists and others. This previous study was not enough to provide adequate baseline parameters. So, advanced research is needed.7

This study focus on the clinical applications of anthropometric data into by the intregration of two antropometric analysis methods. It began with the distribution of questionnaires to obtain a criteria of the most desirable Indonesia facial characteristics, categorized into normal and attractive groups. This method was supported by a multi-media technologies to produce new, fast, accurate, and efficient guidelines especially in plastic surgery. The end result of this research as 3D digital model of the Indonesian female facial types based on antropometric data. This will ultimately yield optimal satisfaction for both the physician and the patients, moreover the outcome can be established as a national and international referral guideline. 


\section{PURPOSE}

The objective of this study is to build an anthropometric database and to apply it in creating a 3D digital model of normal and attractive Indonesian female facial types by the integration of anthropometric analysis methods which will provide useful reference points speedily, accurately and efficiently in facial aesthetic and reconstructive plastic surgery and other interdisciplinary fields.

\section{MATERIAL AND METHOD}

This study is a descriptive, analytical and applied study. The descriptive study described the average size of the Indonesian faces both attractive and normal. The analytic study demonstrated the significant differences between normal and attractive facial types. The applied study used anthropometric data as a basis for the formulation of a 3D digital modeling of Indonesian facial types.

In the first stage of this study, one hundred questionnaires will be distributed to 50 men and 50 women to obtain a criteria of the Indonesian face considered normal and attractive by Likert scale. They chose 200 Deutro-malay students 17-25 years old without past history of facial reconstruction and orthodontics in which 100 women are those with faces considered normal and the other 100 with faces considered attractive. Out of both groups of women, two type juries determined 50 normal and 50 attractive faces. These selected samples undergone lateral cephalometric, photometric, direct anthropometric yielding a quantitave data and will have their photographs taken (figure 2).8,9,10 These was performed by the same examiner and photographer with the same setting and instrument to maintain the consistency of study.

This initial stage is essential to quantify the characteristics of the Indonesian face. In the second stage anthropometric data was analyzed using $t$ test analysis and descriminat test analysis. Data from antropometric and cephalometric measurements combined with computer-aided design technology '3D-menow-3D-max' to produce a digital 3D formula of the Indonesian facial types. The integration was done to create facial morphology in both the normal and attractive concept. In the final stage the 3D image was interpreted by an expert before concluding the end result. The end result may be used as a reference for temporary predictions of surgical outcomes. Correlation analysis between qualitative and quantitative data were performed to get a thorough assessment of the characteristics of normal and attractive Indonesian facial types.

\section{RESULT}

The results consist of three parts i.e 1. Analysis of questionnaires, 2. Analysis of anthropometric measurements and 3. Description of three dimensional model of normal and attractive female face. Analysis of questionnaires about the attractiveness scale showed that there was a variance in the criteria of attractiveness such as side face shape, eyes, eyelashes, mouth and jaw shape in female face between male and female respondents. According to the attractiveness scale, criteria of attractive face were oval face, thin lips, high nose, narrow mouth, prominent cheekbones, narrow jaws, curved eyelashes, eyebrows slanting upward laterally, small teeth and maxillary teeth was aligned with mandibular teeth. Criteria of normal face were square face, thick lips, broad and relatively flat dorsum nose, deficient tip projection of nose, wide mouth, flat cheekbones, wide jaws, straight eyelashes, straight eyebrows, rounded teeth and maxillary teeth protruded than mandibular teeth. This criteria used to determine the subject of study and this study obtained 92 subjects.

Furthermore, 92 subjects were assessed by two groups of juries. The first jury was respondents and the second jury was two plastic surgeons. The assessment by the respondent group were done subjectively and based on visual assessment. This assessment showed 42 subjects of study as normal face criteria and 50 subjects of study as normal face criteria. The second jury (expert) assessed subjects of study objectively that to determine the classification and ranking the samples. The assessment based on normal and attractive face criteria to reduce bias among juries. Scores ranged from 10-100 numbers. The value of the cut of point in this study was 62,42 . According to the cut of point, subjects of study who had value less than or equal to $62.42(\leq 62.42)$ as normal face criteria and subjects who had above 62.42 (> 62.42 ) as attractive face criteria. The results showed that 50 subjects were normal face criteria (average values between $62.29-52.29$ ) and 42 subjects were included attractive criteria (the average value of 73.12 to 62.70 ). This assessment was described in following picture 1 .

Direct anthropometric examination exhibeted that there were 6 variables significant differences between the groups of attractive and normal female face with $\mathrm{p}$ value $<0.05$. The variables were right orbital height (os-or), ala thickness, nasal tip protrusion (sn-prn), mandibular ramus height left (go-cdl), cutaneus lower lip height (sto-sl), lower vermilion height (li-sl) (see table 1 below).

Descriminant test was conducted to determine the parameters of distinguishing between normal and attractive face. This analysis also defined the most influential parameters on the overall facial appearance both on the vertical axis and the horizontal face. There were 5 parameters generated in this test (see table 2 below).

In cephalolometric examination showed that there was significant differences about interincisivus angle value (II) between the two groups of normal and attractive with $\mathrm{p}<0.05$. It means that the position of the maxillary incisors to the mandibular incisors in the normal face more protrusion (procumbent) compared with attractive face. When cephalometric result compared with the Caucasian race, both of groups had a class II skeletal profile with soft tissue profile convex shape and angle interincisivus smaller upper and lower lips more protuded than Caucasian race. Photometric measurement used as complementary of direct antropometric examination. The examination showed three angle measurement sucah as nasofrontal, nasolabial and mentocervical between both of groups. There was significant differences about nasofrontal angle between the two groups of normal and attractive with $\mathrm{p}<0.05$.

The last section of result was description of threedimensional model of normal and attractive female face. 
The selection of the face model was intended as preparation materials to create $3 \mathrm{D}$ model facial type. The selection was done by evaluating the average values for each group either normal or attractive face. Subjects who had it value or close to the average value (means) of group was chosen as a model for normal and attractive face. This model is referred to as the standard model for each group. Furthermore, anthropometric and cephalometric data of model combined with computeraided design technology '3D-menow-3D-max' to produce a digital 3D formula of the Indonesian facial types.

These processes consist of five steps i.e. 1. Image data collection and measurement models, 2. Guidance to determine the data of models, 3. Modeling as enter process data to produce visual data, 4 . Fixing the model as re-examining the suitability of image data, parameters and digital geometry with visual and 5. Finishing output. The end result of this process as an outline description of the lateral and frontal position, 3D picture frame and 3D with texture of the skin as a visualization of concept normal and attractive face criteria. Both of $3 \mathrm{D}$ face models can be seen in the figure $4 \& 5$ below.

\section{DISCUSSION}

Likert scale is one of method that can be used to assess beauty criteria. This scale can describe the attitudes, opinions and perceptions of a person. This study used Likert scale to assess facial aesthetic subjectively. The analysis of questionnaires about the attractiveness scale showed that there was a variance in the criteria of attractiveness such as side face shape, eyes, eyelashes, mouth and jaw shape in female face between male and female respondents. Differences assessment between male and female respondents proved that the concept of beauty is a subjective, relative and varied by sex relative and varied by sex.11 Application of attractive face concept is required for plastic surgery and orthodontics. Therefore, the involvement of a plastic surgeon was needed to judge attractive and normal face in this study. Clinicians' assessment with measurements taken from facial photographs was expected to be able to assess objectively rather than subjectively. 12

Direct and indirect Anthropometric examination has been shown to provide information in detrmining facial proportion and provided the image have been captured in a standardized. The direct examination of anthropometric measurements in this study include 72 landmarks and 23 facial proportion indices. The number of landmark can be used to illustrate in more detail in facial profile Deutro-malay race. This examination can also be used to distinguish between race Caucasian and deutro-malay. According to indirect antropometric (cephalometric) measurements, this study proved that both attractive and normal groups had skeletal class II profile with soft tissue facial profile is more convex, more lip protrusion shape compared to Caucasians. Indonesian facial convexity is related to retrusion of the face, midface and upper jaw protrusion, the more protrusive anterior tooth inclination and the recessive chin. 3

$3 \mathrm{D}$ imaging is now being applied for different orthodontic and maxillofacial assessments: 3D treatment planning, preorthodontic and postorthodontic and/or surgical treatment, evaluation of postoperative swelling,
3D prefabricated arch wires, research, and distinction between different syndromes involving craniofacial deformities. 3D modeling is processed through 2D photo. Several anthropometric landmarks marked manually need to be able to construct surface of the face to be a model of facial animation. 3D modeling in this study has different concept. The process was done through collecting qualitative data followed by quantitative data collection. The end result of this process as an outline description of the lateral and frontal position, 3D picture frame and 3D with texture of the skin as a visualization of concept normal and attractive face criteria. These results as assumed correlation between qualitative and the quantitative values about facial aesthetic..

\section{CONCLUSION}

Anthropometric, photometric and lateral cephalometric measurements played a significant role in differentiating the Indonesian face between normal and attractive also from faces of other races. Three dimension (3D) digital woman models can serve as instruments for characterizing normal and attractive faces visually.

\section{REFERENCES}

[1]. Meenai and Abbas. 'Beauty Measuring System Based on the Divine Ratio', International Conference on User Science and Engineering. 2010. pp. 207-210.(cited: 1 desember 2012).

[2]. Staffieri T.Statistik Bedah Plastik Seluruh Dunia oleh ISAPS 2010. http://m.antaranews.com (Cited: 5 februari 2013).

[3]. Elfiah U., Hutagalung MR., Perdanakusuma D S. Variables of Indonesian Facial Clinical parameters and Cephalometry as Basis Data in Reconstruction of Maxillofacial Trauma. Jurna Kegawatdaruratan. Fakutas Kedokteran Universitas Airlangga. Surabaya. 2011.

[4]. Sucontphunt T., Deng Z., Neumann U. Crafting Personalized Facial Avatars Using Editable Portrait and Photograph Example. EEE Virtual Reality. 14-18 March 2010. Lafayette, Louisiana, USA. (Cited 7 februari 2013).

[5]. Yong-Ha K., Byung-Chae C., Lun-Jou. Facial Contouring Surgery for Asians. Seminar in Plastic surgery. Volume 23. Number 1. 2009. (Cited 23 Januari 2013).

[6]. M.B Stephen. The Art of Poser® and Photoshop®: The Official Guide. Course Technology Press Boston, MA, United States. 2009. (Cited 5 Januari 2013).

[7]. Perdanakusuma DS., Elfiah U., Hutagalung, MR., Putri IL. Variables of Indonesian Facial Antropometry and Cephalometry as Database in Reconstruction of Maxillofacial Trauma. Program studi Bedah Plastik Surabaya. 2012

[8]. Ferrario VF., Sforza C., Schmith JH., Miani JR., Alessandro. Taroni G. Fourier analysis of Human Soft Tissue Facia Shape: Sex Differences in Normal Adults. J Anatomi. 1995. Pp: 593-602.

[9]. Glinka J., Artaria M.D., Koesbardiati T. Metode Pengukuran Manusia. Departemen antropologi. FISIP. Universitas Airlangga. Surabaya. 2008.

[10]. Jain SK, Anand C \& Ghosh SK. Photometric Facial Analysis A Baseline Study. J Anat. Soc. India. 2010. 53 (2) 11-13 (cited: 3 Januari 2013).

[11]. Senna-Fernandes, Vasco. 2008. 'Oriental Anthropometry in Plastic Surgery'. Indian J Plastic Surgery. vol 41(2), pp. 116121

[12]. Ghoddousi H., Edler R., Haers P., Wertheim D., Greenhill D., Comparison of three methods of facial measurement dalam $\mathrm{R}$ Edler., M.Orth., M.Abd. Rahim., Wertheim., D.Greenhill. 2009. The Use of facial Anthropometrics in Aesthetic ssessment. Cleft Palate-Craniofacial Journal. Vol.47. No. 1 January 2010

[13]. Mohammad H. A., Abu Hasan, M I., Hussain S. F. 2011. Cephalometric evaluation for Malaysian Malay by Steiner analysis. Scientific Research and Essay. Vol. 6 (3). Pp $627-$ 634. 4 februari 2011. 


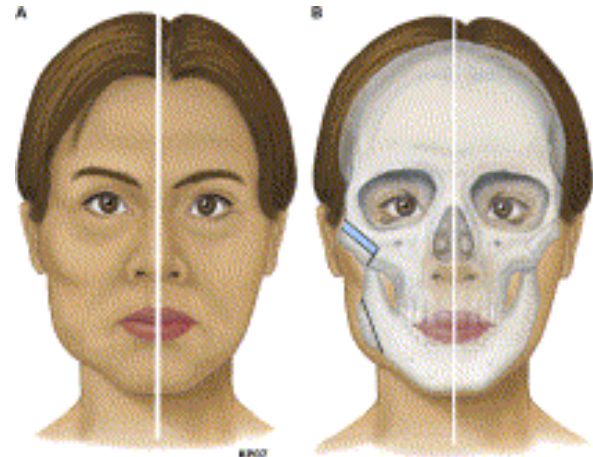

Figure 1. Facial animation model

Source: Yong-Ha K., Byung-Chae C., Lun-Jou. Facial Contouring Surgery for Asians. Seminar in Plastic surgery. Volume 23. Number 1. 2009. (Cited 23 January 2013)

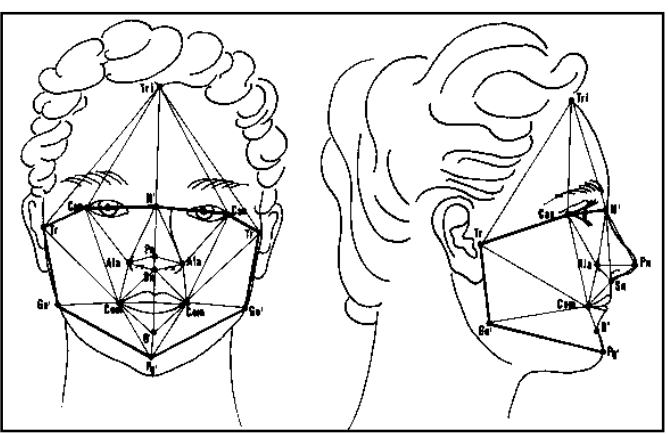

Figure 2. Anthropometric landmarks in facial region. Adapted from: Ferrario VF., Sforza C., Schmith J H., Miani JR., Alessandro., Taroni

G. Fourier analysis of Human Soft Tissue Facial Shape: Sex Differences in Normal Adults. J Anatomy. 1995. Pp: 593-602

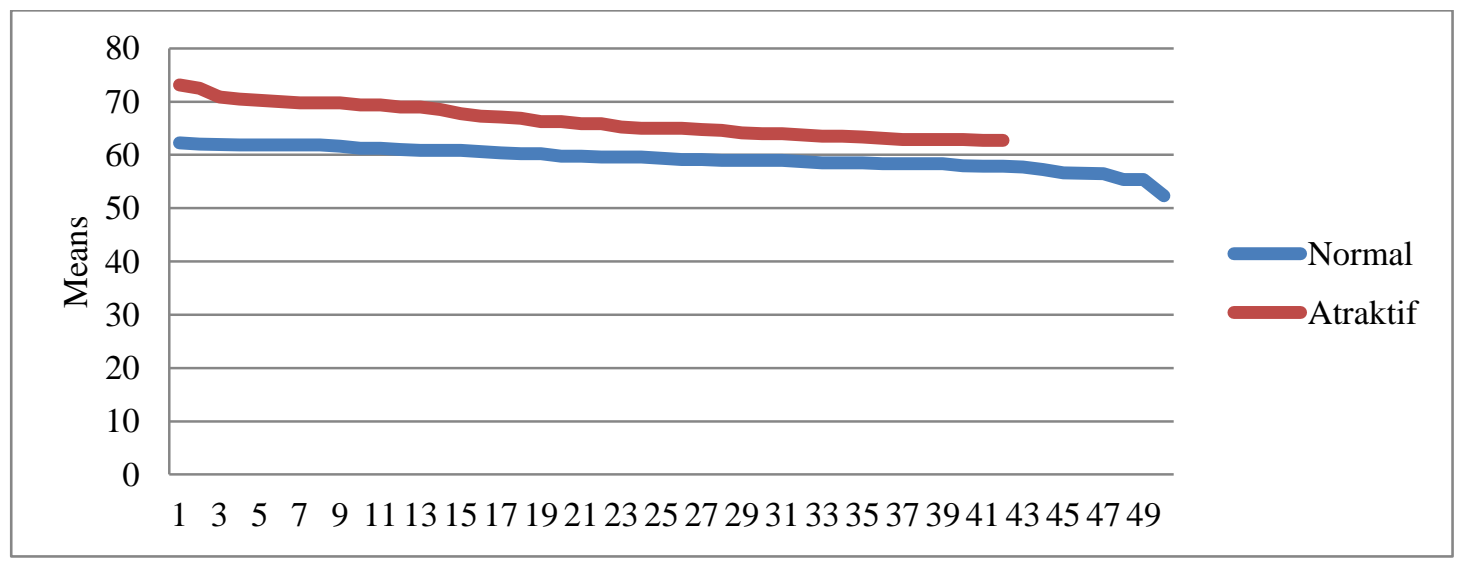

Figure 3. The results of assessment by expert
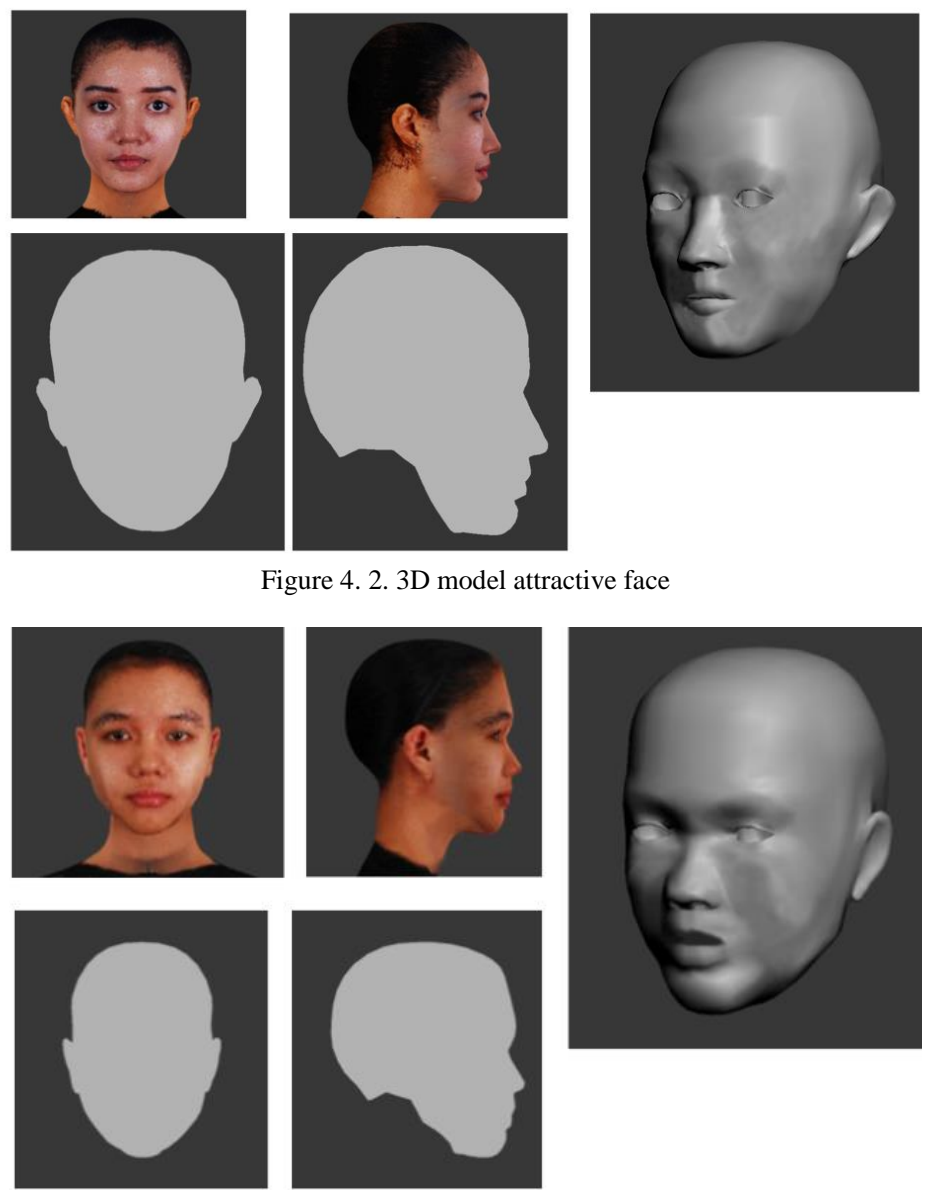

Figure 5. 3D model normal face 
TABLE 1 .

ANTHROPOMETRICIC MEASUREMENTS BETWEEN NORMAL AND ATTRACTIVE FEMALE FACE

\begin{tabular}{llll}
\hline \hline *ariable & $\begin{array}{l}\text { Anthropometric measurements } \\
\text { Normal } \\
n=50\end{array}$ & $\begin{array}{l}\text { Attractive } \\
\mathrm{N}=42\end{array}$ & $\begin{array}{c}\text { Test } \\
\text { Analysis }\end{array}$ \\
\hline os-or (right) & $29.0600 \pm 2.99258(21.00-35.00)$ & $30.4286 \pm 3.35059(22.00-42.00)$ & $\mathrm{P}<0,05$ \\
Ala thickness & $5,2800 \pm 1,14357(3,00-8,00)$ & $4,8095 \pm 1,08736(3,00-8,00)$ & $\mathrm{P}<0,05$ \\
sn-prn & $14,8571 \pm 2,70801(8,00-19,00)$ & $16,0952 \pm 3,01063(7,00-21,00)$ & $\mathrm{P}<0,05$ \\
go-cdl (left) & $52.7347 \pm 5.80508(40.00-66.00)$ & $56.1190 \pm 7.46113(36.00-72.00)$ & $\mathrm{P}<0,05$ \\
li-sl & $6,9800 \pm 2,06516(4,00-14,00)$ & $6,1905 \pm 3,80781(4,00-29,00)$ & $\mathrm{P}<0,05$ \\
sto-sl & $15,3400 \pm 2,96655(7,00-24,00)$ & $14,1667 \pm 2,25147(8,00-19,00)$ & $\mathrm{P}<0,05$ \\
\hline \hline
\end{tabular}

TABLE 2.

THE RESULT OF DISCRIMINANT TEST

\begin{tabular}{lcc}
\hline \multicolumn{3}{c}{ THE RESULT OF DISCRIMINANT TEST } \\
Variable & Profile & \\
\cline { 2 - 3 } & & Normal \\
& & Attractive \\
\hline Nasal bridge index & 2,543 & 2,432 \\
Nasal tip protrusion & 0,634 & 0,871 \\
Binocular width & 0,535 & 0,494 \\
Proportion indices: & 1,422 & 1,279 \\
Lower lip height- mouth width & & \\
& & 1,151 \\
Proportion indices: & 1,230 & \\
Upper lip-nose height & & \\
\hline \hline
\end{tabular}

